\title{
Uma historiadora entre mundos: reflexões da trajetória da Professora Elvira Mea
}

Os estudos africanos no Brasil possuem uma longa estrada e importantes apoiadores, que contribuíram com suas perspectivas e trajetórias pessoais na construção dessa articulação das compreensões dos espaços e sociedades africanas com as sociedades da diáspora. Nesta entrevista que se segue, enfocar-se-á o percurso de vida e de construção de pesquisa e análise histórica de uma intelectual que foi uma das pioneiras nos estudos contemporâneos sobre os Judeus e a Inquisição Portuguesa, e que tem um papel muito importante em evidenciar essas articulações e de compreender os estudos sobre os espaços africanos, brasileiros com as experiências de Portugal. Elvira Cunha de Azevedo Mea é Catedrática de História Moderna e Contemporânea da Faculdade de Letras da Universidade do Porto, sendo pioneira na sua forma de trabalhar, num humanismo muito especial. Suas escolhas e estratégias de aprofundamento historiográfico e intelectual foram enfatizadas na entrevista que concedeu a Patricia Teixeira Santos, professora de História da África da Universidade Federal de São Paulo, em 18 de setembro de 2018, por ocasião da sua vinda em Missão Científica, com apoio do CNPq, na UNIFESP.

Entrevista: Professora Elvira Mea. 
Patricia Teixeira Santos: Prezada Professora Elvira Mea, é com muita alegria que estamos com a senhora aqui, nessa sua missão científica ao Brasil. Somos gratos de estar trabalhando conosco a importância dos Estudos Africanos, e trazendo sua contribuição da sua experiência de ter conduzido um Centro de Estudos Africanos na Universidade do Porto. É muito importante o diálogo que estabelece e coordena com pesquisadores que trabalham a temática das missões cristãs na África. Então eu gostaria de pedir à senhora, inicialmente, que pudesse falar um pouco da sua trajetória, como surgiu seu interesse pela História, de seguir esse percurso como historiadora.

Elvira Mea: Sim, eu acho que desde muito criança eu gostava dessa área porque o meu avô gostava muito de História, nomeadamente História política. Depois, já no Liceu, encontrei uma professora genial de História. Eu, antes, não sabia se ia para o Direito ou para a História, e com 12 anos, mais ou menos, decidi ir para a História. Quando eu tinha 14 anos de idade, essa nossa professora levava-nos a conferências fora do Liceu. Lá, pude ouvir uma conferência de um especialista sobre Judaísmo em Portugal, que era o Amilcar Paulo (acerca de quem escrevi um livro, sobretudo aproveitando, inclusivamente, obras dele, para não ser esquecido). Quando ouvi essa conferência sobre Judaísmo, cheguei à casa e disse: - Vou dedicar-me a investigar o Judaísmo.

Patricia Teixeira Santos: A senhora tinha que idade?

Elvira Mea: Tinha 14/15 anos, tanto que no meu último ano de Liceu, com essa professora, apresentei uma comunicação na Faculdade de Letras, num colóquio de arqueologia. A partir daí, tudo que era trabalho na Faculdade que pudéssemos escolher, optava sempre por coisas sobre os Judeus e, depois, quando acabei a Licenciatura, como queria ir para a carreira diplomática (onde era então obrigatório fazer uma tese), a minha foi O Sefardismo na Cultura Portuguesa, que tive a sorte de ser logo publicada.

Patricia Teixeira Santos: Interessante. E nessa palestra, o que foi motivacional para a senhora seguir esse caminho de estudos Judaicos, o que mais lhe tocou na abordagem do professor?

Elvira Mea: Foi exatamente o pouco que as pessoas sabiam sobre o tema, a quantidade de fontes que estavam por estudar, o preconceito contra os Judeus e a injustiça que havia, inclusivamente, no vocabulário português, em que ainda hoje se diz: "não faças essa Judiaria", "não façam judiarias" ou "você parece um judeu".

Patricia Teixeira Santos: Aqui se diz "Ai, que Judiação".

Elvira Mea: Sim, também. E depois outra coisa que sempre achei graça, ainda miúda, é que como sempre gostei muito de poupar e, às vezes, diziam-me: "pareces um judeu", porque gostava de poupar, e acho que também isso foi uma motivação. Motivou-me também a ideia que iria aprender muito com pessoas que, mesmo sofrendo, continuavam a avançar com uma determinação e resistência fantásticas, e digamos assim, nunca desistiam, essa compreensão da sua resiliência fez-me interessar muito por eles.

Patricia Teixeira Santos: Então a senhora nos relatou que chegou um momento da sua vida em que pensou em fazer uma carreira diplomática e já tinha feito um estudo que já foi publicado. Por que a senhora não seguiu a carreira diplomática e foi para o magistério superior?

Elvira Mea: Não fui porque entretanto conheci o meu marido e se eu fosse para uma carreira diplomática, tinha que ir para 
o estrangeiro. Aliás, já tinha feito um exame para ingressar na carreira, pelo que cheguei a ser chamada para ir para o Chile. Por outro lado, como o diretor da Faculdade me tinha convidado para ser assistente quando acabei o curso, e naquela altura ainda era por convite, e eu recusara, não quis dar o braço a torcer e por isso resolvi candidatar-me ao ensino secundário, e logo no primeiro ano fiz o estágio, ficando então logo professora efetiva no Porto. Depois passei lá quatro anos e tive a sorte de ser convidada para participar numa experiência para o ensino dos $7^{\circ}, 8^{\circ}$ e $9^{\circ}$ anos, que englobava apenas 20 escolas do país, uma em cada distrito e duas em Lisboa e Porto. Aprendi imenso com os colegas muito mais velhos e com muita sabedoria e experiência.

Imagine que a minha colega do Porto era uma grande escritora, a Luisa da Costa.

Patricia Teixeira Santos: A senhora começou a fazer um trabalho no Magistério superior e o tema dos judeus continuou sendo sua abordagem? Como continuou trabalhando essa temática?

Durante muitos anos, a História foi essencialmente masculina de heróis, santos e mártires, e muito pouco do povo anônimo. Quando nós entramos nesse conceito, não podemos esquecer que houve mulheres e homens, portanto não tem nada a ver com aquela concepção que ainda hoje existe de que a História das mulheres está ligada a uma história em que as mulheres são as heroínas, não há heróis nem heroínas na História, não é? É portanto desse ponto de vista que também tenho feito alguns trabalhos sobre mulheres, tão esquecidas, mas sempre integradas na realidade, numa realidade vivida por homens e mulheres.

Patricia Teixeira Santos: Os estudos Judaicos vêm nessa linha?
Elvira Mea: Sim.

Patricia Teixeira Santos: Se a senhora puder falar, ao longo da sua carreira, quais foram as temáticas do estudo judaico que a senhora publicou, se fez contato com associações de estudos judaicos e como suas pesquisas de trabalhos foram se tornando mais conhecidas?

Elvira Mea: Sim, porque na Faculdade, como eu tinha muito boa nota e a tese tinha sido publicada, avancei logo para o doutoramento. E realmente a minha investigação foi muito sobre os cristãos novos, nomeadamente sobre a inquisição, porque havia muito pouco estudo e ainda hoje há. E a minha tese de doutoramento foi exatamente sobre a inquisição de Coimbra. Na altura, havia três tribunais no país, portanto, o sul pertencia ao tribunal de Évora (digamos do Alentejo para baixo), a Inquisição de Lisboa incluía o que hoje chamamos a grande Lisboa mais as colônias todas, e por isso a de Coimbra abrangia todo o norte do país e parte do centro, onde estavam as grandes comunidades de Cristãos Novos. Este foi meu doutoramento: "A Inquisição de Coimbra no Século XVI. A Instituição, os Homens e a Sociedade", que estava há muito esgotada e agora tive a sorte da Fundação Eng. António de Almeida, que então a publicou, há um mês fez nova publicação fac-similada. Entretanto, fui tendo cada vez mais relações com estudos Judaicos em Israel e passei a participar, sempre que possível, em congressos sobre o tema. Em decorrência disso, tornei-me sócia da World Union of the Jewish Studies, com sede em Jerusalém, que de quatro em quatro anos organizava um congresso mundial em que as línguas oficiais eram o Inglês, o Hebraico, o Português e o Idish (a língua dos judeus Asquenazes, quase extinta); o português era língua oficial em função da diáspora dos cristãos-novos portugueses. 
Patricia Teixeira Santos: E a senhora acredita que a sua pesquisa tem ajudado a ressaltar a importância do português na cultura judaica?

Elvira Mea: Sim, até porque ao longo do tempo verifica-se que exatamente os cristãos- novos portugueses foram os grandes embaixadores da cultura portuguesa em todo o mundo e é preciso lembrar que, durante a época moderna até o século XX, estes foram os únicos portugueses que emigraram para a Europa. Na realidade, não foi uma emigração, mas uma fuga, e por isso eram conhecidos não por judeus ou cristãos-novos, mas por portugueses.

O cemitério dos portugueses em Amsterdam é o cemitério de cristãos-novos e dos judeus portugueses, que com eles levaram a língua e a cultura, um dos grandes motores da sua identidade, porque o que os caracteriza e une é precisamente a sua identidade portuguesa. Por isso mesmo, à sua diáspora eles deram um nome de "o desterro de Portugal", um termo tão forte que nos faz pensar e refletir acerca do que teria sido esse grande sofrimento, o enorme desgosto de ter de fugir do seu país, a que eles pertenciam e onde gostariam de ter vivido para sempre.

Patricia Teixeira Santos: Esse termo "desterro", a senhora já comunicou em congressos e causou...

Elvira Mea: Sim, causa sempre muita comoção e sobretudo é impressionante ver-se que aqueles que ficaram em Portugal e resistiram à inquisição até o seu fim, no século $X I X$, foram denominados marranos, o que significa aqueles que resistiram contra tudo e contra todos, persistindo na sua fé judaica, mesmo se a clandestinidade de séculos deteriorara conhecimento e práticas. Já aqueles que fugiram, independentemente de se terem ou não tornado judeus, todos eles continuaram sempre a sentir-se portugueses, de tal maneira que, por exemplo, em 1996, quando houve as comemorações dos 500 anos da expulsão dos Judeus de Portugal, muitos descendentes vieram a Portugal, muitos deles percebiam Português e alguns falavam. Lembro-me sempre de um alemão que falava o português do século XVII porque a família ao longo do tempo tinha passado por vários países europeus, mas às refeições falavam sempre em Português para não esquecer.

Outros, e foram muitos, traziam a chave da casa que sabiam que estava no Porto, ou em Braga, ou noutra terra portuguesa, mas não sabiam exatamente onde nem como, mas sabiam que tinham uma chave de uma casa em Portugal. Isto era impressionante: como guardaram durante séculos as chaves de algo que sabiam que já não existia, mas que era uma lembrança de uma vivência feliz. Ainda hoje, na historiografia judaica, se considera que na Península Ibérica, durante os séculos em que os judeus e depois os cristãos novos lá viveram, foi uma época de ouro para a História judaica.

Patricia Teixeira Santos: Nesse contexto, a senhora já orientava alunos na graduação e na pós-graduação? E houve alunos seus que fizeram estudos na linha de estudos judaicos?

Elvira Mea: Sim, até porque eu tive, depois de doutorada, um seminário sobre "Inquisição, Sociedade e Mentalidades", onde os alunos fizeram trabalhos sobre esses temas, assim como nos outros seminários sobre "Estudos Locais e Regionais" e "Minorias Religiosas e de Pensamento", que também dirigi. Participei também, entre outros, no seminário de História do Brasil, pois durante anos lecionei essa cadeira.

Patricia Teixeira Santos: A senhora poderia nos falar de alguns alunos que 
seguiram profissionalmente nesses estudos judaicos ou que fizeram trabalhos que a senhora considera contribuição para a área de História?

Elvira Mea: Sim, eu tive alunos que fizeram, por exemplo, sobre os cristãos-novos em Viana, Trancoso, Setúbal etc., e sobre os cristãos-velhos do Porto, por exemplo; um aluno fez um ótimo mestrado, até ganhou o prêmio "Artur Magalhães Basto". O título era "Andarilhos do Pecado - Religiosidade dos Cristãos-Velhos Portuenses (Século XVII)". Percebeu-se, então, que um dos grandes pecados dos cristãos-velhos do Porto era exatamente a homossexualidade, sobretudo gente de uma alta posição social. Esse tipo de pesquisa tem no Brasil o grande especialista, o Prof. Luiz Mott, um amigo e colega, com quem convivi muito quando estávamos a preparar o doutoramento no arquivo da Torre do Tombo.

É interessante e até divertido lembrar que havia um cônego da Sé do Porto que no século XVII gostava de ser chamado Izabelita, e tinha os seus pajens que usavam uma espécie de pó de arroz. Mas o importante dessa tese foi sobretudo provar que antes da revolução de 1640 uma série de nobres e gente importante da cidade, que ia frequentemente a Lisboa, não era propriamente de patriotas que iam desestabilizar a sociedade promovendo ou participando em motins, mas iam a encontros gays e isso foi uma bomba.

Isso foi muito interessante porque desvendou-se e percebeu-se outro Porto que era perfeitamente desconhecido, que chocava e que estava ligado exatamente a pessoas importantes.

Eu lembro exatamente que no século XVII um nobre da casa de Ramalde, que é uma casa que ainda hoje existe, muito bonita, no Porto, tinha outra casa na Rua das Flores, uma das ruas principais de então, e que quando passavam jovens, rapazes, ele assobiava e dizia piropos (galanteios), até que uma vez fê-lo com o diretor da alfândega. Este, furioso, fez queixa dele, pelo que acabou por ser preso, mas normalmente essas pessoas, quando eram da alta estirpe, não tinham uma pena muito grande.

Patricia Teixeira Santos: E professora, fazendo esse trabalho com a sensibilidade de perceber as chamadas "pessoas comuns", como a senhora foi se direcionando e chegando aos estudos Africanos?

Elvira Mea: Em primeiro lugar, porque tive um aluno ótimo de Cabo Verde que me ajudou a alugar lá uma casa em S. Vicente, onde passei férias com a família e tive a oportunidade de visitar o país, em 1980, portanto, cinco anos depois da independência. Como lecionava também a disciplina História dos Descobrimentos e da Expansão Portuguesa, foi um deslumbramento, não só pelo país em si, mas pelas pessoas e pelo momento histórico que eu consegui viver, porque, ao contrário do que aconteceu em outros territórios recém-independentes, em Cabo Verde foram abertas as portas a todos indiscriminadamente e, por isso, como eu já disse, eles tinham embaixada dos EUA, Rússia e da China, que eram vizinhas umas da outras.

Houve uma solidariedade entre as pessoas, um Leitmotif que era a importância de Cabo Verde, a sua riqueza, que estava no capital humano e por isso a prioridade no conhecimento, que tinha de avançar, a educação, os estudos superiores etc.

E vi, portanto, nesse grande momento de solidariedade, que quem sabia mais, ensinava quem sabia menos, de maneira a dar um salto na sua campanha para um país mais rico, em função do seu conhecimento e da sua competência, a única maneira de 
possibilitar ir deixando de ser um país muito pobre sob o ponto de vista econômico, o que parecia ser um destino fatal.

Patricia Teixeira Santos: E a partir disso, como a senhora começou, de fato, a atuar, orientar e organizar o CEAUP?

Elvira Mea: Sim eu fui para o CEAUP por acaso, na medida em que se formou um Centro de Estudos Africanos que era de toda a Universidade porque pluridisciplinar, mas estava sediado na Faculdade de Letras. Então, pediram voluntários de História interessados em participar nesse centro, eu fui uma das pessoas. De um momento para outro resolveu-se a nível da Universidade fazer um mestrado de Estudos Africanos que incluía várias Faculdades e, logo a seguir, um doutoramento em Estudos Africanos.

Patricia Teixeira Santos: Isso foi em qual ano?

Elvira Mea: Foi em anos 96/97 e o mestrado começou em 2000. Então vi-me, de um dia para outro, a ter que dar no ano letivo seguinte História da África, o que foi, digamos, um susto, muito estudo, mas foi muito bom porque os outros colegas de outras áreas também nunca tinham lecionado África. Por exemplo, o meu colega de Economia já tinha estado inclusivamente em África, era mais velho, era pró-reitor, mas nunca tinha lecionado economia do continente Africano, o professor de Antropologia a mesma coisa, o de Sociologia o mesmo; a única pessoa que já tinha experiência era uma colega professora de Literatura Africana. Quando nos reuníamos, percebemos que a grande dificuldade estava em que nenhum de nós era propriamente especialista em África, o que nos uniu muito.

Depois colocava-se a questão de não haver uma licenciatura em Estudos Africanos e, portanto, os nossos alunos do mestrado vinham também das várias áreas, como História, Sociologia, Geografia, Economia, Arquitetura, Engenharia, mas estavam longe da temática do Mestrado.

Nesse aspecto, acho que foi algo que superamos, e superamos bem, porque cada um de nós percebeu que tentar explicar África em perspectivas diferentes não deixava o foco ser sempre África. Chegámos mesmo no primeiro e no segundo ano a irmos assistir, de vez em quando, às aulas uns dos outros, conversávamos sobre aquilo que estávamos a dar e como estávamos a dar.

Por exemplo, eu fui várias vezes a aulas sobre economia porque, sendo de História, não tinha uma visão específica da evolução econômica, às vezes os conteúdos entrelaçavam-se, mas outras vezes não, o mesmo aconteceu com os outros colegas e assim constituímos uma equipe. Com os alunos também aconteceu o mesmo, formaram uma equipe em que a grande maioria eram africanos. Por seu turno, docentes e discentes cientes dessas dificuldades, constituímos uma equipe para superá-las, onde os alunos conheciam melhor África do que nós, mas nós tínhamos os estudos teóricos embora poucos tivessem estado em algum país africano.

Portanto, houve logo uma multiplicidade de interesses e de conhecimentos que inclusivamente levava, a que, depressa, como é costume, os alunos africanos criassem uma cumplicidade entre si, um companheirismo solidário, que existiu também entre nós, professores, que também nos vimos a braços com algo de novo que estávamos a estudar e isso também nos uniu porque ninguém ali era especialista de África, portanto tínhamos muito que estudar, e quanto mais soubéssemos uns dos outros, melhor era.

Patricia Teixeira Santos: Então foi muito rico? E essa riqueza desse convivio, dessa 
troca intelectual e afetiva vai se expressar em obras. Que obras? Se você pudesse falar da revista.

Elvira Mea: Sim, muitíssimo. Houve logo uma revista, a Africana Studia, do Centro de Estudos Africanos da Universidade do Porto, que ainda hoje é de muito prestígio exatamente porque desde o início procurámos que várias pessoas e especialistas em várias áreas participassem, fizemos muitos encontros, em Portugal e em África. Fizemos convênios em Cabo Verde, Senegal etc., com a ajuda da Cátedra Humanismo Latino criada pela Fondazione Cassa Marca de Treviso, a que tive a honra de presidir. Realizámos mestrados na Praia e em S. Vicente (Cabo Verde), foi a primeira vez que a Universidade do Porto saiu das suas portas para fazer um mestrado fora e em que os professores não ganharam nada, deslocando-se nas férias da Páscoa, Natal e quando havia exames ou frequências. Para a maioria de nós, nem sequer contou para o respectivo serviço docente.

Portanto, íamos cada um por sua vez ensinar em horário pós-laboral, de maneira que os alunos, normalmente pessoas que já tinham sua profissão, com família, não perdiam nada. Consegui que a Reitoria diminuísse a propina (taxa) em 50\%, na medida em que os alunos só vinham defender a tese ao Porto, e o governo de Cabo Verde pagava a viagem e as estadias dos professores.

Sobre os docentes, também consegui na altura, não âmbito da Cooperação que durante 2 ou 3 anos ela pagasse as viagens. No segundo ano, já com a tese escolhida e com seus orientadores, os alunos elaboravam a tese, contactando os respectivos professores orientadores pela internet. Fui coordenadora desses mestrados, ia lá de dois em dois meses para tirar dúvidas, resolver problemas e levar e trazer dados, livros etc. dos professores para os alunos e vice-versa.

O que verificamos é que praticamente $90 \%$ ou mais defenderam a suas teses de muito boa qualidade, diferentes umas das outras; nenhum mestrando desistiu, apesar de todas as dificuldades havidas, desde a falta de bibliografia, às constantes falhas na internet e outros. Lembro, por exemplo, que no primeiro mestrado vários alunos conseguiram vir defender as suas teses, porque interviemos e conseguiu-se que as viagens fossem pagas por empresas de construção portuguesa e outros tipos de empresas.

Essas pessoas foram também uma motivação especial para outros alunos perceberem que quem quer muito e é persistente, faz; um exemplo fantástico para os outros mestrandos, como os portugueses.

Por outro lado, ainda antes dos mestrados, exatamente porque eu tinha uma relação especial com Cabo Verde, consegui que a Faculdade aceitasse alunos com bacharelado em História para fazerem mais um ano e meio até terem a licenciatura, considerando que tinham feito as cadeiras e os programas de História do Instituto do ISE (Instituto Superior de Educação), tinham sido decalcados do nosso, portanto não era difícil considerar um número de cadeiras para eles depois fazerem, no Porto, a licenciatura. O departamento de Geografia também aceitou o desafio.

Isso foi de tal maneira vantajoso que eles em um ano e meio acabaram de fazer a licenciatura, já que ainda não havia Universidade no país. Acontece também que verificamos que esses alunos tinham uma boa competência, suficiente para fazer sem grandes problemas a licenciatura.

Patricia Teixeira Santos: Que interessante esse processo de construção. E a senhora 
lembra, vendo esse processo de orientar, quais eram as temáticas que os alunos mais traziam ou que eles tinham muita preocupação de pensar no mestrado?

Elvira Mea: Em relação aos estudos deles, todos estavam interessados e tinham facilidade em desenvolver temas sobre suas próprias terras; quem tinha problemas eram os portugueses, que tinham que fazer alguma coisa sobre África, e não sabiam nada e nunca tinham ido à África, portanto era mais difícil de escolher os temas. A maioria dos africanos, quando vinha para o mestrado, já tinha um objetivo muito concreto sobre o que fazer, temas como os transportes, a economia do cotidiano, tradições, religião nos vários cambiantes, como os evangélicos, emigração, trabalho forçado etc.; houve de tudo um pouco e com interesse muito grande pelo seu próprio país, tanto que eles não tinham dificuldade porque no fundo eles é que conheciam seu país, e cabia-nos dar-lhes as ferramentas específicas de cada ciência, método e bibliografia, criando uma simbiose muito rica para todos.

Patricia Teixeira Santos: No CEAUP, quanto tempo se dedicou esse trabalho de formação, qualificação de pós-graduação com o pessoal de Cabo Verde?

Elvira Mea: Houve dois ou três mestrados em Cabo Verde, depois continuaram sempre a haver mestrados no Porto, que incluía estudantes dos PALOP e estrangeiros de diversos outros países interessados nos nossos Estudos Africanos.

Patricia Teixeira Santos: Dessa experiência do Centro de Estudos Africanos, o que a senhora achou mais significativo?

Elvira Mea: Em primeiro lugar, ao ligar-me ao CEAUP ainda nos anos 90 , fui vice presidente e depois presidente do Centro durante
11 anos. Penso que as experiências mais ricas foram as de conviver com alunos africanos, revelando aquilo que eu sempre considerei que havia, um Humanismo Africano, e daí participei em vários eventos da Fundação Cassamarca de Treviso, que tinha estudos ligados ao Humanismos Latino e, através desta, promovi eventos nos sítios mais variados, como já referi.

Por exemplo, tive o gosto de organizar um encontro sobre o Humanismo Latino em Nova York em 2000, e no mesmo ano, fizemos, um pouco antes, um encontro sobre os Humanismos Latino e Africano em Cabo Verde e outro sobre a mesma temática no Senegal. Organizei ainda outro evento, mas esse já com a vertente um pouco diferente, sobre os Humanismos Latino e Oriental em Macau.

A respeito do encontro sobre os Humanismos Latino e Africano, foi alguma coisa em que entraram investigadores diferentes, sobretudo muitos italianos que nunca tinham pensado que havia um Humanismo Africano. Nessa altura, participaram pessoas de vários países, que ensinavam sobretudo literatura, línguas, História da África, mas em perspectivas muito diferentes, muito mais conservadoras. Portanto foi para eles e para nós muito profícuo constatarmos que era preciso fazer essa reflexão, que nos propormos a isso era o caminho certo, mesmo que alguns tenham ficado chocados, pois a sua visão de África era preconceituosa e superficial, alinhada nos chavões habituais.

Patricia Teixeira Santos: Professora, nesse período que a senhora estava no CEAUP, começou aqui, no Brasil, uma busca que se tornou mais sistemática, a partir da Lei 10.639, de 2003, que institui o ensino de História da África e da história Afro-Brasileira em todos os níveis da Educação. Como a senhora percebeu esse movimento nosso? 
Elvira Mea: Nós organizamos, com a Universidade Federal da Bahia e a Fundação Pedro Calmon, um encontro, penso que também em 2006, em que exatamente debatemos os problemas ligados a essa nova situação, com a participação das Universidades de Salvador, na Bahia. Havia uma parte que era reservada aos professores e outra parte em que os alunos apresentavam já trabalhos. Fiquei admirada com o interesse dos alunos e com a qualidade dos trabalhos. Foi nessa altura que tivemos a percepção de que se estava a construir no Brasil alguma coisa inédita para a História e Cultura brasileiras. Tendo sido professora durante muitos anos de História e Cultura brasileira, vi que iria resolver uma lacuna imensa. Foi um momento histórico em que - Brasil estava também a perceber melhor a sua identidade graças a esses tipos de estudos e que, de uma vez por todas, penso eu, à medida em que se vai avançando na investigação, no ensino e na aprendizagem, as pessoas vão acabando com os fantasmas do protecionismo, dos colonialismos, da escravatura etc.

Ao compreendermos o que aconteceu, deixamos de ter fantasmas e monstros na nossa frente para perceber que houve uma caminhada muitas vezes com muitos obstáculos, mas que continua a fazer-se e, portanto, o Brasil tem uma potencialidade humana riquíssima. Aliás, nós vemos hoje que os povos que continuaram virados sobre si mesmos e sobre o seu umbigo têm imensas dificuldades em perceber os outros e até a si mesmos porque não tiveram uma perspectiva de relacionamentos, de encontros e desencontros com outros povos, outras mentalidades etc.

Por isso mesmo o Brasil, hoje em dia, é um país com um capital humano extraordinário, com potencialidades criativas que nós vemos no cotidiano, fora de série e que, à medida que formos cada vez mais percebendo até que ponto as culturas africanas, as culturas indígenas e a culturas europeias se relacionaram entre si, perceberemos cada vez melhor como o Brasil é um dos países onde exatamente a mundividência pode ser mais abrangente e onde um secular e contínuo encontro de Humanismos, africano, europeu, americano, oriental, são uma realidade e uma riqueza imensa na sua profundidade e diversidade.

Patricia Teixeira Santos: Professora, a senhora falou muito na perspectiva do Humanismo, como a senhora entende o Humanismo?

O Humanismo está ligado ao Renascimento, em que, como todos sabemos, se entende que o Humanismo latino é o Humanismo europeu que nasceu na Itália, ligado às culturas clássicas, com determinadas características e, à medida que o tempo passou, se pensou no humanismo latino como uma visão europeia da vida e dos valores etc., sem pensar que os outros continentes, nomeadamente a África, também tinham seus humanismos, uma maneira humana de ver as coisas, mas uma maneira humana diferente do Humanismo latino. Por exemplo, houve ao longo do tempo, nas culturas africanas, a ideia de que exatamente a riqueza de um povo, de uma família, era o capital humano, o número de parentes que tem, enquanto que na época moderna o humanismo latino, europeu, digamos, já estava muito ligado ao lucro, ao desenvolvimento econômico, ao capitalismo.

Não podemos esquecer que então os africanos diziam que a família dos europeus era o dinheiro, daí a evidência do choque entre os dois humanismos, em que, inclusivamente, como nós sabemos, sob o ponto de vista político e não só, a democracia era 
vista de maneira muito diferente de hoje, considerando-se então que os africanos não a conheciam.

A verdade é que, muito embora as inúmeras culturas africanas existentes então na época moderna fossem muito diversas, havia alguns denominadores entre várias, como, por exemplo, sob o ponto de vista político, a sucessão de alguém, que comandava ou que governava, fazia-se através do diálogo que um grupo de pessoas, os mais velhos, que, com a sua experiência, estabelecia a discussão, o diálogo, de modo a chegarem a pontos comuns e a deliberar, o que muitas vezes demorava o seu tempo, uma pura perda de tempo para os europeus, mas, na realidade, depois de essa discussão chegar a uma conclusão, determinava que normalmente a pessoa escolhida, o tipo de contestação ou até oposição fosse totalmente diferente. Maneiras muito próprias de conceber e fazer política, mas frequentemente, ao escolher o diálogo como via para uma solução, estariam os africanos assim tão longe do conceito de democracia?

Mas lá está, essa maneira incluía um diálogo que, na mesma época, na Europa, não existia, porque em muitos casos, aos reis sucediam os seus filhos, netos etc. Em África, de uma maneira geral, mas, claro, não podemos generalizar totalmente, em princípio sucedia a pessoa mais capaz, a pessoa que a maioria considerava a melhor, portanto hoje vamos ver: isso é ou não é Humanismo?

$\mathrm{Na}$ altura, os historiadores europeus achavam que isso era um atraso porque demorava muito tempo a resolver, até porque a forma como se vê o tempo é totalmente diferente do Humanismo Latino, ou melhor, do Humanismo Europeu.

O Humanismo Africano tem uma concepcão de tempo diferente que nós não deve- mos valorizar ou desvalorizar porque isso faz parte da História, devemos compreender por que se entende o tempo de maneira diferente. A História é uma ciência humana onde não pode haver juízos de valor.

Patricia Teixeira Santos: E nessa chave do tempo eu faço a última pergunta. Hoje, na posição que a senhora se encontra, com todo o percurso já feito e que ainda continua a fazer, como a senhora integrou em sua vida os estudos judaicos, os estudos africanos e os outros demais temas que percorreu, como isso se integra na Elvira Mea de hoje?

Elvira Mea: Eu acho que foi muito enriquecedor porque o fato de não me especializar só num tema permitiu-me uma maior abrangência, e a História é feita de inúmeras relações e variáveis. Como sabemos, as ciências humanas têm uma multiplicidade de variáveis que não têm as outras ciências, por isso mesmo é que a História está sempre a fazer-se de acordo com as variáveis que se nos deparam, os modos como as relacionamos, assim temos chance de compreendemos cada vez melhor.

Eu acho que ter enveredado por estudos diferentes permitiu-me e permite-me relacionar e entender as situações sob vários pontos de vista, inclusivamente o facto de ter lecionado cadeiras muito diferentes, como a História dos Descobrimentos e da Expansão ou as Minorias Religiosas e de Pensamento, o seu estudo e pesquisa constituíram uma base para hoje continuar a estudar e, sobretudo agora, que estou aposentada, sem a pressão do tempo para ensinar ou para escrever, o que me dá maior qualidade de vida. Portanto aquele desejo, por exemplo, de ler uma revista científica, que antes nós só tínhamos tempo para ler aquela parte que precisávamos e não as outras, agora posso aproveitar muito 
mais, alargar o conhecimento para além do imediatamente útil. A possibilidade de estudar é muito maior e daí todos os anos, em cursos que estou a dar, mudo os temas porque isso vai permitir não facilitar as coisas, mas fazer algo de novo. E isso implica que vou ter que estudar coisas diferentes que ainda não sabia. Pretendo, nos meus próximos anos, dedicar-me ao Brasil contemporâneo. Poderei debruçar-me sobre - Brasil República e o Brasil ditadura, coisa que eu só fiz a nível pessoal e não para poder ensinar. Já tinha há anos realizado outro curso anual até o Império.

Estou muitíssimo entusiasmada porque só em estar aqui já aprendi tanto, tenho tantas perguntas a fazer aos livros e aos autores, portanto estou a aproveitar muitíssimo esta minha estadia.

Patricia Teixeira Santos: A senhora chegou em um contexto político atual em que temos que refletir sobre a forma como funciona o nosso sistema presidencialista, sobretudo a partir do impeachment de Dilma Rousseff. Como a senhora avalia a nossa situação política neste momento?

Elvira Mea: Muito difícil, porque exatamente temos que pensar que o Brasil é um continente com muitos problemas que não são propriamente de um país, mas são quase de um continente, pois, por exemplo, a nivel ambiental tem o problema das geadas, tem os problemas das secas, tem os problemas das inundações. Agora se imaginarmos em termos humanos, então é uma multiplicidade muito maior, mas eu queria dizer o seguinte: neste dilema, o fato de o Brasil, em relação a trinta ou a quarenta anos atrás, já ter uma opinião pública, penso que é de prever que cada vez terá mais e mais gente mais consciente da situação e da sua responsabilidade como cidadãos na continuidade e progresso do país.
Por sua vez, os Estudos Africanos vão cada vez permitir mais mostrar que existe uma cultura brasileira, que é de uma originalidade ímpar e, a partir daí, acho que os brasileiros resolverão os seus próprios problemas e seus dilemas tendo em conta que muitos dos defeitos que nós falamos etc., existem nos outros países ao mesmo nível, só que o Brasil é muito grande e, como tal, a dimensão de uma corrupção não é comparável com outros, como Portugal, França, Itália etc., que têm a sua própria corrupção, mas num território muito menor. Os interesses mesquinhos, a exploração, existem a nível global, mas a própria riqueza natural do Brasil já catapulta ambições e tentações de todo o gênero. Portanto aquilo que hoje aqui os brasileiros consideram uma enormidade está de acordo com o país enorme. Os outros também têm os seus pecados, os golpes baixos, na proporção humana de cada um.

Vamos torcer para que esta situação se resolva, sobretudo tendo em consideração uma coisa muito importante, a democracia. Os brasileiros sabem quanto lhes custou chegar à democracia, se pensarem nisso, apesar de haver grandes problemas, o caminho tem só um sentido. Infelizmente, haverá muitos milhares e milhões que não sabem o que é democracia e não têm o dever de saber, somos nós que temos obrigação de ensinar o que é democracia, sobretudo com o nosso exemplo de vida.

(Transcrição realizada por Tamires Sodré de Paula - UNIFESP) 


$$
\text { ¿. Plurri }
$$

